\title{
GESTÃO DE ESTOQUE COMO FERRAMENTA DE CONTROLE GERENCIAL PARA AS EMPRESAS
}

\section{ARTIGO ORIGINAL}

MONTEIRO, Geovania dos Anjos ${ }^{1}$, SILVA, Prossineke Colares $\mathrm{da}^{2}$, ANDRADE, Armando Rodrigo ${ }^{3}$, SANTOS, Maria lolene Silva dos $^{4}$, ROBERTO, José Carlos Alves $^{5}$, SERRA, Meg Rocha da Cunha ${ }^{6}$, LOPES, Nelânia Ferreira ${ }^{7}$

MONTEIRO, Geovania dos Anjos. Et al. Gestão de estoque como ferramenta de controle gerencial para as empresas. Revista Científica Multidisciplinar Núcleo do Conhecimento. Ano 06, Ed. 11, Vol. 03, pp. 63-79. Novembro de 2021. ISSN: 24480959,

Link de acesso:

https://www.nucleodoconhecimento.com.br/contabilidade/controle-gerencial, DOI: 10.32749/nucleodoconhecimento.com.br/contabilidade/controle-gerencial

\section{RESUMO}

O presente artigo é baseado em uma pesquisa bibliográfica que tem como objetivo principal: descrever a importância do gerenciamento dos estoques para as empresas, uma vez que a maioria das empresas tem a necessidade de informações relacionadas à gestão de estoques, e que por isso não possuem dados suficientes para investir nessa área. Trata-se como algo relevante para o negócio, sendo os estoques a principal fonte de capital de giro das empresas. Por isso, houve a necessidade de realizar este estudo, a fim de gerar conhecimento e dar suporte para

\footnotetext{
${ }^{1}$ Graduanda do curso de Ciências Contábeis.

${ }^{2}$ Graduando do curso de Ciências Contábeis.

${ }^{3}$ Graduando do curso de ciências contábeis.

${ }^{4}$ Graduando do curso de ciências contábeis.

${ }^{5}$ Orientador. Mestre em Engenharia de produção. Especialista Logística empresarial. Graduado em Administração com Ênfase em Marketing.

${ }^{6}$ Orientadora. Mestra em Engenharia de Processos Industriais pela UFPA, especialista em Controladoria e Auditoria Contábil pelo Ciesa (2020), graduada em Ciências Contábeis pelo Centro Universitário do Norte (2010). Graduada em Ciências Econômicas pelo Centro Universitário do Norte (2006).

${ }^{7}$ Orientadora. Especialista em Auditoria Contábil, Financeira e Tributária e Graduada em Ciências Contábeis.
}

RC: 100697

Disponível em: https://www.nucleodoconhecimento.com.br/contabilidade/controlegerencial 
o negócio. Portanto, para auxiliar a pesquisa foi levantada a seguinte pergunta problema: Como a gestão de estoque pode influenciar nas tomadas de decisões empresariais? Utilizou-se uma metodologia de natureza aplicada, caracterizada quanto aos fins, como descritiva e, quanto aos meios, como bibliográfica, utilizandose de levantamento de dados de livros, revistas e artigos. Diante disso, os resultados esperados para este artigo são mostrar como a gestão de estoque pode influenciar no modo de pensar e agir dos empresários e quais os métodos devem ser adotados para utilizar-se dos benefícios deste tipo de gestão.

Palavras-chave: gestão, estoques, controle, ferramentas, tomada de decisões.

\section{INTRODUÇÃO}

Com o avanço da tecnologia as ferramentas de gestão tem sido uma solução para muitas empresas se manterem vivas no mercado, pois são alternativas eficientes que ajudam os gestores a suprir com a grande demanda do mercado e a conseguir vantagens em relação aos demais concorrentes.

Tadeu et al. (2010) relata que para conseguir ter vantagem no mercado mundial, os gestores precisam ter conhecimento e controle sobre todos os setores da empresa, principalmente o estoque que é uma parte importante do ativo da empresa e influencia diretamente tanto o setor produtivo como o setor financeiro, e consequentemente o capital de giro da empresa.

Para o desenvolvimento do estudo, buscou-se responder a seguinte questão norteadora: Como a gestão de estoque pode influenciar nas tomadas de decisões empresariais? Desta forma, os dados levantados devem trazer informações que possam auxiliar os gestores no processo de gestão de estoques.

Deste modo, este artigo tem como objetivo geral: descrever sobre a importância do gerenciamento dos estoques para as organizações, e como ela pode influenciar diretamente nos processos produtivos e administrativos. E aliado ao objetivo geral, 
vinculou-se os seguintes objetivos específicos: o conceito de estoque, os tipos de estoques e como podem ser divididos os itens através da classificação ABC.

Portanto, todas as informações coletadas servem para motivar os empresários a ter conhecimento desta área, a fim de auxiliar na implantação de métodos de controle que ajudem o desenvolvimento do negócio. Para a execução do presente artigo foi utilizado uma pesquisa bibliográfica, descritiva de natureza pura. Usando como base conceitos já existentes relacionados ao assunto, porém trazendo ao público novas ideias que podem ampliar ainda mais o conhecimento sobre o tema.

\section{FUNDAMENTAÇÃO TEÓRICA}

De acordo com Zambello et al. (2018), a fundamentação teórica é um elemento indispensável para a construção de um trabalho científico, pois ajuda no desenvolvimento e na coleta de dados, através da análise de livros, artigos, entre outros. Deste modo, ela serve para que o autor esclareça quais foram as bases utilizadas para a compreensão e formulação das todas as ideias que serão apresentadas.

\subsection{CONTABILIDADE GERENCIAL}

A contabilidade passou por grandes mudanças ao longo dos anos, causadas principalmente pela evolução tecnológica, essas mudanças possibilitaram a disseminação de ramos ou técnicas contábeis que eram anteriormente consideradas desnecessárias e assim desvalorizadas no setor empresarial. Um desses ramos da contabilidade que cresceu bastante foi a contabilidade gerencial, que deixou de ser considerada apenas um demonstrativo de números, para ser uma ferramenta que auxilia a tomada de decisões nas organizações.

Segundo Crepaldi (2017), a contabilidade gerencial é uma importante ferramenta para a gestão empresarial, que analisa as informações fornecidas por outros ramos 
contábeis, para gerar dados ou relatórios que sirvam de base para as tomadas de decisões dentro da entidade empresarial.

Para Padoveze (2012), seu o objetivo é fornecer informações contábeis através da análise de dados, variações orçamentárias e indicadores que ajudam a empresa a ter conhecimento sobre sua capacidade de cumprir com suas obrigações, e assim esclarecer sua visão sobre as tendências de mercado e o aumento das demandas e transmitir essas informações obtidas para toda a entidade.

Segundo Atrill (2014), a contabilidade gerencial é mais voltada para os usuários internos da organização, sendo eles os gestores, administradores e os próprios funcionários, tendo como foco principal fornecer suporte e informações para esses usuários, e moldar os dados coletados conforme as necessidades da entidade.

Entretanto, para usufruir dessas informações é preciso um profissional capacitado que irá auxiliar a gestão empresarial. Para Padoveze (2012), o contador gerencial precisa ter conhecimento sobre todos os setores das empresas e sobre outras áreas, para assegurar que as informações coletadas sejam de utilidades para a tomada de decisões por parte da administração.

\subsection{CONCEITOS DE ESTOQUE}

Segundo o Paoleschi (2013), o estoque pode ser definido como todo material ou produto que a empresa usa e precisa armazenar em suas instalações, como, por exemplo, matéria-prima, produtos em processamento, produtos acabados disponíveis para venda e todos os outros materiais e insumos que serão utilizados para a fabricação de um produto.

Já conforme Femenick (2011), o estoque é um conjunto de contas que faz parte do ativo circulante e deve expressar o número total de itens usados para vender ou produzir bens, de acordo com as transações comerciais normais da entidade. 
Segundo Tadeu et al. (2010), o estoque representa a maior parte dos recursos físicos e financeiros da empresa e um dos ativos de maior valor e importância para a gestão, pois influenciam diretamente na produção, nas vendas e a manter o melhor nível de serviço para o consumidor.

Entretanto, mesmo com tantas definições o conceito do estoque ainda é bastante discutido, pois pode variar de acordo com várias características, como o tipo de negócio da empresa, a forma de armazenar os materiais e entre outros, contudo, independente do ramo do negócio os estoques devem ser administrados e controlados para garantir um bom rendimento para entidade.

\subsection{GESTÃO DE ESTOQUE}

Para Tadeu et al. (2010), a gestão de estoque possui uma evolução bastante relacionada com a logística, embora ambos os termos possuam o mesmo conceito. Essa evolução é causada principalmente pela mudança do modo de pensar da mentalidade empresarial, que deixaram de lado o modo distorcido de como tratavam suas mercadorias, e ampliaram a visão para um novo conceito de estocar e controlar os itens armazenados nos estoques.

Para Femenick (2011) esta gestão é responsável por acompanhar, controlar e organizar os estoques, e assim equilibrar a forma de como os recursos serão utilizados.

Segundo Paoleschi (2013) fazer um bom planejamento dos estoques é essencial para as empresas, pois, através desse planejamento os gestores terão total acesso e controle sobre todos os processos produtivos e a forma de estocagem dos produtos. Este controle auxilia na hora de eliminar os desperdícios de produto e de tempo, e ajuda a manter um bom relacionamento com o cliente.

RC: 100697

Disponível em: https://www.nucleodoconhecimento.com.br/contabilidade/controlegerencial 


\subsection{CLASSIFICAÇÕES DOS ESTOQUES}

Com base nas ideias de Tadeu et al. (2010), os estoques podem ser divididos segundo sua empregabilidade, assim são classificados em quatro principais grupos: estoques de matérias-primas, estoques de produtos em elaboração, estoques de materiais auxiliares e estoques de produtos acabados.

\subsubsection{ESTOQUE DE MATÉRIA-PRIMA}

Para Paoleschi (2013), as matérias-primas são todos os itens ou materiais que serão processados ou transformados e participarão de forma direta no processo produtivo da empresa até chegar ao produto acabado e utilizado no processo produtivo.

Segundo Femenick (2011), estes estoques são formados por todos os insumos estocados ou armazenados que serão utilizados no processo produtivo da empresa, e formarão parte do processo de transformação do produto final.

\subsubsection{ESTOQUE DE PRODUTOS EM PROCESSO}

De acordo Tadeu et al. (2010), estes estoques são compostos por diversos produtos que ainda estão em produção, portanto, ainda não incorporam o produto final, também pertencem a esse grupo todos os custos aplicados nos produtos em elaboração.

Para Paoleschi (2013), os estoques de produtos em processo se referem aos produtos semiacabados que passaram somente por uma das partes do processo produtivo, porém não estão finalizados e não podem ser comercializados.

\subsubsection{ESTOQUE DE MATERIAIS AUXILIARES}

Para Tadeu et al. (2010), os estoques de materiais auxiliares são todos os itens envolvidos em todo o processo empresarial, que, porém, não participam diretamente do processo produtivo do produto acabado. 
De acordo com Femenick (2011), estes estoques também são denominados materiais indiretos já que auxiliam o processo da fabricação sem serem incorporados ao produto final.

\subsubsection{ESTOQUE DE PRODUTOS ACABADOS}

Segundo Tadeu et al. (2010), os estoques de produtos acabados são compostos por todos os produtos já finalizados que serão disponibilizados para a venda. Ou seja, o estoque de produto acabado consiste em todos os itens que já passaram por todas as fases do processo produtivo e serão utilizados para a comercialização.

Para Paoleschi (2013), estes estoques são de suma importância para as empresas, pois seus produtos irão atender diretamente ao consumidor final e toda a demanda do mercado.

\subsection{FERRAMENTAS DE GESTÃO NO CONTROLE DE ESTOQUE}

De acordo com Paoleschi (2013), o controle de estoques é um investimento de grande escala que requer muita atenção e tempo para as empresas, pois ele gerencia atividades que estão inteiramente ligadas ao processo produtivo, e refletem bastante na saúde financeira do negócio. Assim, fazer um bom planejamento é fundamental para os empresários que querem se manter vivos no mercado e se manter com as grandes demandas.

Para chagas (2010), é essencial que se faça um controle na entrada e na saída das mercadorias, para assim determinar o Custo das Mercadorias Vendidas (CMV). Para isso foi criado métodos contábeis que auxiliam as empresas a conhecer e controlar todos os itens que pertencem aos seus estoques.

\subsubsection{PEPS}

Segundo Ribeiro (2013), PEPS também conhecido como Fifo é um método que possui uma ideia bem simples, onde os itens são organizados segundo sua ordem

Disponível em: https://www.nucleodoconhecimento.com.br/contabilidade/controlegerencial 
de chegada, deste modo, o primeiro "item" que entrar no estoque também será o primeiro a sair do estoque. Na tabela 1 apresenta-se uma ficha de controle de estoque utilizando-se o método PEPS.

Tabela 1: Método PEPS

\section{FICHA DE CONTROLE DE ESTOQUE}

PRODUTO: A

\begin{tabular}{|c|c|c|c|c|c|c|c|c|}
\hline \multirow{3}{*}{ Data } & \multicolumn{3}{|c|}{ ENTRADA } & \multicolumn{3}{|l|}{ SAÍDA } & \multicolumn{2}{|c|}{ SALDO } \\
\hline & \multirow{2}{*}{ Quant } & Custo & Custo & \multirow{2}{*}{ Quant } & Custo & Custo & \multirow[t]{2}{*}{ Quant } & \multirow{2}{*}{$\begin{array}{l}\text { Custo } \\
\text { Total }\end{array}$} \\
\hline & & Unitário & Total & & Unitário & Total & & \\
\hline 02/08 & 30 & 15,00 & 450,00 & - & - & & 30 & $\begin{array}{l}450,0 \\
0\end{array}$ \\
\hline 03/08 & - & - & - & 15 & 20,00 & 375,00 & 11 & 75,00 \\
\hline- & - & - & - & 4 & 15,00 & 60,00 & 7 & 15,00 \\
\hline $04 / 08$ & 40 & 20,00 & 800,00 & - & - & - & 42 & $\begin{array}{l}815,0 \\
0\end{array}$ \\
\hline $05 / 08$ & - & - & - & 20 & 25,00 & 500,00 & 22 & $\begin{array}{l}315,0 \\
0\end{array}$ \\
\hline 06/08 & - & - & - & 10 & 15,00 & 150,00 & 12 & $\begin{array}{l}165,0 \\
0\end{array}$ \\
\hline 08/08 & 25 & 20,00 & 500,00 & - & - & - & 37 & $\begin{array}{l}665,0 \\
0\end{array}$ \\
\hline 09/08 & - & - & - & 14 & 25 & 350,00 & 23 & $\begin{array}{l}315,0 \\
0\end{array}$ \\
\hline $\begin{array}{l}\text { TOTA } \\
\text { L }\end{array}$ & & & $\begin{array}{l}1.750,0 \\
0\end{array}$ & & & $\begin{array}{l}1.435,0 \\
0\end{array}$ & & $\begin{array}{l}315,0 \\
0\end{array}$ \\
\hline
\end{tabular}

Fonte: Elaborado pelo autor

Disponível em: https://www.nucleodoconhecimento.com.br/contabilidade/controlegerencial 
De acordo com Chagas (2010), as entradas são referentes às compras do produto $A$, enquanto as saídas são as vendas deste produto e na coluna do saldo está a quantidade armazenada. A cada venda, é realizada a retirada do produto mais antigo, isto é, o primeiro a ser comprado, desta forma, o primeiro "item" a ser comprado sempre será o primeiro a ser vendido. O método PEPS utiliza um cálculo bem simples onde se tem:

$\mathrm{LOB}=\mathrm{RBV}-\mathrm{CMV}$

Onde:

$\mathrm{RBV}=$ Receita Bruta das Vendas

$\mathrm{CMV}=$ Custo das Mercadorias Vendidas

LOB= Lucro Operacional Bruto

$\mathrm{CMV}=$ Estoque Inicial $(\mathrm{EI})+$ Compras do período $(\mathrm{C})-$ Estoque Final $(\mathrm{EF})$

\subsubsection{UEPS}

Segundo Chagas (2010) o método UEPS também conhecido como Lifo possui um modo de controle contrário ao PEPS, onde o último "item" a entrar no estoque será o primeiro a sair do estoque. Deste modo, o total do estoque será calculado através do preço unitário do último que entrou, ou seja, da compra mais recente que possui muitas vezes o preço maior. Na tabela 2 apresenta-se um modelo do método UEPS.

Tabela 2: Método UEPS

\begin{tabular}{|c|c|c|c|c|c|c|c|c|}
\hline \multirow{3}{*}{$\begin{array}{l}\text { Dat } \\
\text { a }\end{array}$} & \multicolumn{3}{|c|}{ ENTRADAS } & \multicolumn{2}{|c|}{ SAÍDAS/VENDAS } & \multicolumn{3}{|l|}{ SALDOS } \\
\hline & Quantida & Preço & Total & Quantida & Total & Quantida & Preço & Total \\
\hline & de & $\begin{array}{l}\text { Unitár } \\
\text { io }\end{array}$ & & de & & de & $\begin{array}{l}\text { Unitár } \\
\text { io }\end{array}$ & \\
\hline E.I & 100 & 50,00 & 5.000 & - & - & 100 & 50,00 & $5.000,0$ \\
\hline
\end{tabular}

RC: 100697

Disponível em: https://www.nucleodoconhecimento.com.br/contabilidade/controlegerencial 


\begin{tabular}{|c|c|c|c|c|c|c|c|c|}
\hline & & & 00 & & & & & 0 \\
\hline $\begin{array}{l}01.1 \\
1\end{array}$ & 120 & 55,00 & $\begin{array}{l}6.600, \\
00\end{array}$ & - & - & 120 & 55,00 & $\begin{array}{l}6.600,0 \\
0\end{array}$ \\
\hline \multirow{3}{*}{$\begin{array}{l}03.1 \\
1\end{array}$} & & & & & & 220 & & $\begin{array}{l}11.000, \\
00\end{array}$ \\
\hline & - & - & - & 60 & $\begin{array}{l}4.200,0 \\
0\end{array}$ & 60 & 55,00 & $\begin{array}{l}3.300,0 \\
0\end{array}$ \\
\hline & & & & & & 160 & & $\begin{array}{l}8.300,0 \\
0\end{array}$ \\
\hline \multirow[t]{2}{*}{$\begin{array}{l}05.1 \\
1\end{array}$} & 90 & 60,00 & $\begin{array}{l}5.400, \\
00\end{array}$ & - & - & 90 & 60,00 & $\begin{array}{l}5.400,0 \\
0\end{array}$ \\
\hline & & & & & & 250 & & $\begin{array}{l}13.700, \\
00\end{array}$ \\
\hline \multirow[t]{2}{*}{$\begin{array}{l}15.1 \\
1\end{array}$} & 80 & 65,00 & $\begin{array}{l}5.200, \\
00\end{array}$ & - & - & 80 & 65,00 & $\begin{array}{l}5.200,0 \\
0\end{array}$ \\
\hline & & & & & & 330 & & $\begin{array}{l}18.900, \\
00\end{array}$ \\
\hline \multirow[t]{3}{*}{$\begin{array}{l}20.1 \\
1\end{array}$} & - & - & - & 160 & $\begin{array}{l}12.800, \\
00\end{array}$ & 80 & 65,00 & $\begin{array}{l}5.200,0 \\
0\end{array}$ \\
\hline & & & & & & 80 & 60,00 & $\begin{array}{l}4.800,0 \\
0\end{array}$ \\
\hline & & & & & & 170 & & $\begin{array}{l}8.900,0 \\
0\end{array}$ \\
\hline \multirow[t]{4}{*}{$\begin{array}{l}25.1 \\
1\end{array}$} & - & - & - & 100 & $\begin{array}{l}8.200,0 \\
0\end{array}$ & 10 & 60,00 & 600,00 \\
\hline & & & & & & 60 & 55,00 & $\begin{array}{l}3.300,0 \\
0\end{array}$ \\
\hline & & & & & & 30 & 50,00 & $\begin{array}{l}1.500,0 \\
0\end{array}$ \\
\hline & & & & & & 70 & & $3.500,0$ \\
\hline
\end{tabular}

RC: 100697

Disponível em: https://www.nucleodoconhecimento.com.br/contabilidade/controlegerencial 
\begin{tabular}{|l|l|l|l|l|}
\hline $\mid$ & & 0
\end{tabular}

\section{0}

Fonte: Modificado de Chagas (2010, p.117).

Segundo Ribeiro (2013), no método UEPS o preço unitário do saldo será representado pelo preço unitário da última compra que entrou no estoque, deste modo, o CMV apresentará uma quantidade maior, causado pelo custo que se entra em maior quantidade, o que consequentemente proporcionará um lucro menor.

\subsubsection{CUSTO MÉDIO}

Segundo Chagas (2010), o método da média ponderada trata-se de um método bem simples e mais realista que possibilita um maior controle sobre os valores das mercadorias que a empresa tem armazenadas no estoque, através de resultados mais rápidos que revelam as flutuações ocorridas nos preços das mercadorias.

Para Ribeiro (2013), este método pode ser dividido em dois modos, o primeiro é denominado custo médio ponderado móvel, onde o custo do produto é medido sobre as variações causadas pela aquisição de novos produtos, deste modo, a cada compra é preciso aprimorar um novo valor de custos unitário para esse produto.

O segundo método é denominado custo médio ponderado fixo, onde o custo médio pode ser representado pela soma dos custos totais do investimento no produto dividido pelo total de itens comprados. Na tabela 3 está uma representação do método da média ponderada ou custo médio.

Tabela 3: Método da Média Ponderada

\begin{tabular}{|c|c|c|c|c|c|c|c|c|}
\hline \multirow{3}{*}{ Data } & \multicolumn{3}{|c|}{ ENTRADAS } & \multicolumn{2}{|c|}{$\begin{array}{l}\text { SAÍDAS/VENDA } \\
\mathrm{S}\end{array}$} & \multicolumn{3}{|c|}{ SALDOS } \\
\hline & \multirow[t]{2}{*}{ Quant } & Preço & \multirow[t]{2}{*}{ Total } & \multirow{2}{*}{ Quant } & \multirow[t]{2}{*}{ Total } & \multirow[t]{2}{*}{ Quant } & Preço & \multirow[t]{2}{*}{ Total } \\
\hline & & $\begin{array}{l}\text { Unitári } \\
0\end{array}$ & & & & & $\begin{array}{l}\text { Unitári } \\
\text { o }\end{array}$ & \\
\hline
\end{tabular}

RC: 100697

Disponível em: https://www.nucleodoconhecimento.com.br/contabilidade/controlegerencial 


\begin{tabular}{|c|c|c|c|c|c|c|c|c|}
\hline E.I & 100 & 50,00 & $\begin{array}{l}5.000,0 \\
0\end{array}$ & - & - & 100 & 50,00 & $5.000,00$ \\
\hline \multirow[t]{2}{*}{$\begin{array}{l}01.1 \\
1\end{array}$} & 120 & 55,00 & $\begin{array}{l}6.600,0 \\
0\end{array}$ & - & - & 120 & 55,00 & $6.600,00$ \\
\hline & & & & & & 220 & & $\begin{array}{l}11.600,0 \\
0\end{array}$ \\
\hline \multirow[t]{2}{*}{$\begin{array}{l}03.1 \\
1\end{array}$} & - & - & - & 60 & $4.200,00$ & 60 & 52,73 & $3.163,80$ \\
\hline & & & & & & 160 & & $8.436,20$ \\
\hline \multirow[t]{2}{*}{$\begin{array}{l}05.1 \\
1\end{array}$} & 90 & 60,00 & $\begin{array}{l}5.400,0 \\
0\end{array}$ & - & - & 90 & 60,00 & $5.400,00$ \\
\hline & & & & & & 250 & & $\begin{array}{l}13.836,2 \\
0\end{array}$ \\
\hline \multirow[t]{2}{*}{$\begin{array}{l}15.1 \\
1\end{array}$} & 80 & 65,00 & $\begin{array}{l}5.200,0 \\
0\end{array}$ & & & 80 & 65,00 & $5.200,00$ \\
\hline & & & & & & 330 & & $\begin{array}{l}19.036,2 \\
0\end{array}$ \\
\hline $\begin{array}{l}20.1 \\
1\end{array}$ & - & - & - & 160 & $\begin{array}{l}12.800,0 \\
0\end{array}$ & 160 & 57,68 & $9.228,80$ \\
\hline \multirow[t]{2}{*}{$\begin{array}{l}25.1 \\
1\end{array}$} & & & & 100 & $8.200,00$ & 100 & 57,68 & $5.768,00$ \\
\hline & & & & & & 70 & & $4.039,40$ \\
\hline
\end{tabular}

Fonte: Modificado de Chagas (2010, p.119).

\subsection{MÉTODOS QUE AUXILIAM O CONTROLE DE ESTOQUE}

Segundo Tadeu et al. (2010), o planejamento dos estoques é um fator imprescindível para o gerenciamento de uma empresa, pois é através desse planejamento que os gestores poderão analisar todos os dados coletados, os quais

Disponível em: https://www.nucleodoconhecimento.com.br/contabilidade/controlegerencial 
auxiliaram as futuras tomadas de decisões. Para isso, é preciso primeiro de ferramentas que possam ajudar a ter controle sobre tudo que envolve os estoques.

\subsubsection{INVENTÁRIO}

Para Paoleschi (2013), o inventário é uma ferramenta essencial para o controle de estoque, pois através dela se faz um levantamento e uma contagem de todas as mercadorias que se encontram estocadas nos estoques. Desta forma, podem-se identificar as entradas e as saídas dos materiais, e quantificar exatamente quantos produtos há armazenados nos estoques e assim evitar as compras excessivas de matérias-primas ou a falta destas. Sendo assim, fazer inventários ajudará a diminuir os gastos e a evitar desperdícios, visto que, ao separar, identificar e organizar todos os itens armazenados, os gestores poderão basear-se nestes dados para tomar decisões importantes para o negócio.

Segundo Chagas (2010), existem dois tipos de inventários, o primeiro é chamado de inventário periódico, no qual é feito somente no final de cada período e, portanto, os valores dos custos totais são apresentados somente no final do exercício. Este método utiliza-se de uma fórmula para calcular os custos das mercadorias vendidas (CMV):

$\mathrm{CMV}=$ Estoque inicial + Compras Líquidas - Estoque Final.

O segundo é chamado de inventário permanente, que consiste no acompanhamento de todas as movimentações que podem suceder no estoque, utilizando-se dos métodos de controle PEPS, UEPS e Custo Médio. Este inventário é considerado mais eficaz, pois controla todas as entradas e saídas do estoque fornecendo informações em tempo real.

\subsubsection{CURVA ABC}

De acordo com Paoleschi (2013), a curva ABC é uma forma de classificar os itens para determinar quais são os mais importantes para a empresa, que apresentam 
grande valor de consumo, a fim de pôr mais atenção nesses itens, uma vez que por serem mais relevantes consomem mais custos. Eles são divididos em: classe $A$ que são os mais importantes que precisam de muita atenção; classe B que são itens intermediários; e classe $\mathrm{C}$ que são os itens que têm menor valor de consumo, porém são os que estão em maior quantidade.

Tabela 4: Curva ABC

CURVA ABC

\begin{tabular}{|l|l|l|l|l|l|}
\hline Produtos & $\begin{array}{l}\text { Custo Mensal do } \\
\text { Item }\end{array}$ & Acumulados & $\%$ do $\%$ & Classificação \\
& no Estoque & & & & \\
\hline $\mathbf{1}$ & $370.000,00$ & $\mathrm{R} \$ 370.000,00$ & $17,87 \%$ & 17,87 & $\mathrm{~A}$ \\
\hline $\mathbf{2}$ & $350.000,00$ & $\mathrm{R} \$ 720.000,00$ & $16,91 \%$ & 34,78 & $\mathrm{~A}$ \\
$\mathbf{3}$ & $330.000,00$ & $\mathrm{R} \$ 1.050 .000,00$ & $15,94 \%$ & 50,72 & $\mathrm{~A}$ \\
\hline $\mathbf{4}$ & $310.000,00$ & $\mathrm{R} \$ 1.360 .000,00$ & $14,98 \%$ & 65,70 & $\mathrm{~A}$ \\
\hline $\mathbf{5}$ & $115.000,00$ & $\mathrm{R} \$ 1.475 .000,00$ & $5,56 \%$ & 71,26 & $\mathrm{~B}$ \\
\hline $\mathbf{6}$ & $95.000,00$ & $\mathrm{R} \$ 1.570 .000,00$ & $4,59 \%$ & 75,85 & $\mathrm{~B}$ \\
\hline $\mathbf{7}$ & $90.000,00$ & $\mathrm{R} \$ 1.660 .000,00$ & $4,35 \%$ & 80,91 & $\mathrm{~B}$ \\
\hline $\mathbf{8}$ & $80.000,00$ & $\mathrm{R} \$ 1.740 .000,00$ & $3,86 \%$ & 84,06 & $\mathrm{~B}$ \\
\hline $\mathbf{9}$ & $75.000,00$ & $\mathrm{R} \$ 1.815 .000,00$ & $3,62 \%$ & 87,68 & $\mathrm{~B}$ \\
\hline $\mathbf{1 0}$ & $70.000,00$ & $\mathrm{R} \$ 1.885 .000,00$ & $3,38 \%$ & 91,06 & $\mathrm{~B}$ \\
\hline $\mathbf{1 1}$ & $23.000,00$ & $\mathrm{R} \$ 1.908 .000,00$ & $1,11 \%$ & 92,17 & $\mathrm{C}$ \\
\hline $\mathbf{1 2}$ & $22.000,00$ & $\mathrm{R} \$ 1.930 .000,00$ & $1,06 \%$ & 93,24 & $\mathrm{C}$ \\
\hline $\mathbf{1 3}$ & $21.000,00$ & $\mathrm{R} \$ 1.951 .000,00$ & $1,01 \%$ & 94,25 & $\mathrm{C}$ \\
\hline $\mathbf{1 4}$ & $19.000,00$ & $\mathrm{R} \$ 1.970 .000,00$ & $0,92 \%$ & 95,17 & $\mathrm{C}$ \\
\hline $\mathbf{1 5}$ & $18.000,00$ & $\mathrm{R} \$ 1.988 .000,00$ & $0,87 \%$ & 96,04 & $\mathrm{C}$ \\
\hline $\mathbf{1 6}$ & $18.000,00$ & $\mathrm{R} \$ 2.006 .000,00$ & $0,87 \%$ & 96,91 & $\mathrm{C}$ \\
\hline $\mathbf{1 7}$ & $17.000,00$ & $\mathrm{R} \$ 2.023 .000,00$ & $0,82 \%$ & 97,73 & $\mathrm{C}$ \\
\hline $\mathbf{1 8}$ & $16.000,00$ & $\mathrm{R} \$ 2.039 .000,00$ & $0,77 \%$ & 98,50 & $\mathrm{C}$ \\
\hline $\mathbf{1 9}$ & $16.000,00$ & $\mathrm{R} \$ 2.055 .000,00$ & $0,77 \%$ & 99,28 & $\mathrm{C}$ \\
\hline & & & & & \\
\hline
\end{tabular}

RC: 100697

Disponível em: https://www.nucleodoconhecimento.com.br/contabilidade/controlegerencial 


\begin{tabular}{l|l|l|l|l|l|}
$\mathbf{2 0}$ & $15.000,00$ & $\mathrm{R} \$ 2.070 .000,00$ & $0,72 \%$ & 100,00 & $\mathrm{C}$ \\
\hline TOTAL & $\mathrm{R} \$ 2.070 .000,00$ & & & & \\
\multicolumn{2}{l|}{ Classificação: $\mathbf{A}=\mathbf{2 0} \%$ dos itens com $\mathbf{6 5 \%}$ do valor total }
\end{tabular}

Classificação: $B=\mathbf{3 0} \%$ dos itens com $\mathbf{2 5} \%$ do valor total

Classificação: $\mathrm{C}=\mathbf{5 0} \%$ dos itens com $\mathbf{1 0} \%$ do valor total

Fonte: Modificado de Paoleschi (2013 p. 36)

\subsubsection{GIRO DE ESTOQUE}

Para Paoleschi (2013), o giro de estoque é um indicador muito importante para a administração dos estoques, pois ele mostra a quantidade de vezes que as mercadorias estiveram em circulação, evitando desperdícios e gastos causados pelo acúmulo de muitas mercadorias paradas no estoque e consequentemente os defeitos nos produtos, que podem ter sido gerados devido ao tempo que a mercadoria ficou parada. Além disso, esta ferramenta mostra o equilíbrio entre as vendas e compras, e ajuda na saúde financeira do negócio.

Segundo Femenick (2011), o giro de estoque serve para medir a rotatividade dos estoques em relação aos produtos em um determinado período, desta forma, se mede a quantidade de vezes que um determinado item teve entrada e saída no estoque. Esta rotatividade pode ser calculada através de uma fórmula bem simples:

$\mathrm{G}=\underline{\mathrm{CMV}}=$ Número de vezes de giro do estoque SME

\subsubsection{ESTOQUE MÍNIMO}

Segundo Paoleschi (2013), o estoque mínimo visa indicar a quantidade mínima que se devem armazenar as mercadorias no estoque, é um método de controle que 
ajuda a gestão a ter mais conhecimento e controle sobre os produtos que são vendidos e os que estão estocados.

Para Femenick (2011), esta ferramenta serve para medir qual é o mínimo de itens que se precisa para suprir as necessidades de produção e venda. Este tipo de estoque ajuda a evitar os desperdícios com o excesso de produto ou a carência destes e traz mais eficiência para o processo produtivo. Para usar este método o gestor deve fazer inventários para obter informações necessárias e administrá-las de forma eficiente.

\subsubsection{ESTOQUE MÁXIMO}

De acordo com Paoleschi (2013), o estoque máximo serve para delimitar a quantidade máxima de estoques de produtos, e assim determinar o tamanho da área do estoque e a quantidade máxima que se devem armazenar as mercadorias, portanto, o estoque máximo vai pela lógica contrária ao do estoque mínimo. Este método é calculado através da soma do estoque mínimo com o maior lote de compra.

Segundo Femenick (2011), este tipo de estoque serve como um indicador de grande importância para os gestores, pois através dele se pode evitar alguns problemas que ocorrem nas empresas, como a falta de espaço físico para armazenar as mercadorias, custos de estoque parado e desperdícios de produtos.

\section{MATERIAIS E MÉTODOS}

\subsection{PROCEDIMENTOS METODOLÓGICOS}

Os procedimentos metodológicos são um conjunto de técnicas de pesquisas utilizadas para definir quais serão os métodos utilizados para a construção do trabalho. De acordo com Gil (2010), a pesquisa precisa de técnicas que a ajudem a atingir o seu objetivo através da verificação de todos os passos dados para a obtenção do conhecimento.

RC: 100697

Disponível em: https://www.nucleodoconhecimento.com.br/contabilidade/controlegerencial 


\subsubsection{QUANTO À NATUREZA}

Quanto a sua natureza, as pesquisas podem ser puras ou aplicadas. De acordo com Leão (2016), a pesquisa pura tem como objetivo apenas aprofundar o conhecimento sobre determinado assunto, já a pesquisa aplicada busca encontrar soluções sobre o assunto para serem aplicados na realidade.

Já segundo Barros (2014), a pesquisa pura ou básica não pretende alterar a realidade de um determinado fenômeno, mas somente aprimorar seu conhecimento e satisfazer a necessidade de compreender ainda mais a realidade do fenômeno. Enquanto a pesquisa aplicada ou prática procura resultados que possam trazer soluções para determinados problemas.

A pesquisa utilizada no trabalho caracteriza-se como pesquisa aplicada, pois visa gerar conhecimento sobre o assunto abordado para introduzir métodos que ajudem na gestão empresarial, através dos dados coletados e das abordagens utilizadas para visão anterior sobre o assunto e facilitar sua compreensão.

\subsubsection{QUANTO AOS FINS}

Segundo Gil (2010), as pesquisas com base nos seus fins podem ser divididas em descritivas, exploratórias e explicativas. A pesquisa descritiva é aquela cuja finalidade é descrever as características de um determinado assunto através de coletas de dados, questionários ou da observação do próprio autor.

Para Severino (2013), a pesquisa exploratória procura criar hipóteses e ideias para a compreensão do assunto, enquanto a pesquisa explicativa tem como base descobrir fatos novos e aprofundá-los na realidade.

Em relação aos seus fins, a pesquisa será descritiva, pois abordará sobre um assunto que já é conhecido, com o objetivo de esclarecer, registrar e interpretar todos os dados coletados, para uma maior compreensão e conhecimento sobre o assunto e conectá-lo à sociedade, mas sem interferir ou modificar a realidade. 


\subsubsection{QUANTO AOS MEIOS}

De acordo com Fonseca (2012), a pesquisa bibliográfica é aquela que possui uma base teórica e que se utiliza de dados já elaborados por outros autores, porém este tipo de pesquisa não pode ser elaborado como apenas um resumo do que já foi escrito, e sim como uma nova ideia sobre o assunto.

Já segundo Gil (2010), a pesquisa bibliográfica visa fornecer informações já desenvolvidas e colocar o pesquisador em contato com essas informações, e assim proporcionar um caminho mais fácil para a coleta de dados. Desta forma, ela tem sua fundamentação baseada em livros, artigos, monografias, entre outros.

Desde modo, para execução deste artigo, foi utilizada uma pesquisa bibliográfica com base em ideias de outros autores, contudo, se fez uma nova abordagem sobre o assunto, apresentando um novo aspecto que precisa ser discutido e utilizado.

\section{CONSIDERAÇÕES FINAIS}

Quando se iniciou o trabalho de pesquisa constatou-se que atualmente grandes partes das organizações não consideravam o controle dos estoques como uma ferramenta essencial para o empreendimento, por isso era importante discutir sobre a importância da gestão de estoques para as organizações.

Diante disto, a pesquisa teve como objetivo geral: descrever como o gerenciamento dos estoques pode influenciar diretamente nas tomadas de decisões das empresas. Constou-se que o objetivo foi atendido, pois, efetivamente o trabalho conseguiu demonstrar que uma boa gestão de estoques, além de trazer benefícios para a entidade, também se torna uma vantagem competitiva no mercado mundial.

A pesquisa partiu de hipóteses bem práticas que revelam quais as ferramentas que auxiliam o controle de estoque, e verificou que essas ferramentas são essenciais para a gestão, pois as empresas precisam ter inventários que controlam as entradas 
e as saídas de materiais, assim como necessitam de uma rotatividade dos estoques e, ainda, a como classificar todos os itens armazenados.

Em resposta à questão feita na pesquisa: Como a gestão de estoque pode influenciar nas tomadas de decisões empresariais? A gestão é um processo que ajuda e auxilia na gestão de estoques, podendo identificar quais são os itens de maior impacto dentro da empresa, controlar as entradas e saídas de mercadorias e diminuir os custos e desperdícios. Sendo assim, ela representa a capacidade da empresa de organizar e controlar a quantidade de cada produto em determinado momento e ajuda na saúde financeira da organização.

Portanto, as informações expostas são fundamentais para os gestores e podem ser aplicadas em qualquer ramo, seja ele industrial ou comercial, pois através delas os empresários terão uma visão mais ampla sobre o futuro do negócio e saberão atender da melhor forma as demandas e o consumidor em geral. Desta forma, a pesquisa tornou-se relevante para outros interessados no assunto.

\section{REFERÊNCIAS}

ATRILL, P.; MCLANEY, E. Contabilidade gerencial para tomada de decisão. São Paulo: Saraiva, 2014.

BARROS, A. J. da S.; LEHFELD, N. A. de S. Fundamentos de Metodologia Científica. 3 ed. São Paulo: Pearson Prentice Hall, 2014.

CHAGAS, J. G. das. Contabilidade Geral Simplificada: Demonstrações financeiras após alterações na lei S.A. e as sociedades empresárias à luz do novo Código Civil. 2 ed. São Paulo: Saraiva, 2010.

CREPALDI, S. A. Contabilidade gerencial: teoria e prática. 8. ed. São Paulo: Atlas, 2017. 
FEMENICK, T. R. Contabilidade Avançada e Dinâmica Gerencial. 2 ed. Curitiba: Juruá, 2011.

FONSECA, R. C. V. da. Metodologia do trabalho Científico. 1 ed. Curitiba, PR IESDE Brasil, 2012.

GIL, A. C. Como Elaborar Projetos de Pesquisa. 4 ed. São Paulo: Atlas, 2010.

LEÃO, L. M. Metodologia do Estudo e Pesquisa: facilitando a vida dos estudantes, professores e pesquisadores. Petrópolis, RJ: Vozes, 2017.

PADOVEZE, C. L. Contabilidade gerencial: um enfoque em sistema de informação contábil. Curitiba: IESDE Brasil, 2012.

PAOLESCHI, B. Almoxarifado e Gestão de Estoques. 2 ed. São Paulo: Érica, 2013.

RIBEIRO, O. M. Contabilidade Intermediária. 4 ed. São Paulo: Saraiva, 2013.

SEVERINO, A. J. Metodologia do Trabalho Científico. 1 ed. São Paulo: Cortez, 2013.

TADEU, H. et al. Gestão de Estoques: fundamentos, modelos matemáticos e melhorias práticas aplicadas. 1 ed. Cengage Learnin, 2010.

ZAMBELlO, A. V. et al. Metodologia da Pesquisa e do Trabalho Científico. 1 ed. Penápolis, São Paulo: FUNEPE, 2018.

Enviado: Outubro, 2021.

Aprovado: Novembro, 2021. 